\title{
ENEMALAR VE ENEMA FORMÜLASYONLARINDA YENİ GELİŞMELER ENEMAS AND NEW DEVELOPMENTS IN ENEMAFORMULATIONS
}

\author{
Asuman BOZKIR* \\ Müge KILIÇARSLAN * \\ *Ankara Üniversitesi Eczacıllk Fakültesi Farmasötik Teknoloji \\ Anabilim Dalı, 06100 , Tandoğan, ANKARA
}

ÖZET :

Bu derlemede hem lokal hem de sistemik olarak etkin bir rektal dozaj şekli olan enemaların tanımı, özellikleri ve siniflandırlmast yapılmıştır. Bunun yanısıra, rektal uygulamaların avantaj ve dezavantajlarından bahsederek değisşik enema formülasyonlarıyla ilgili klinik ve teknolojik araştırmalar özetlenmiştir.

Anahtar Kelimeler : Enema,Rektal Absorpsiyon , Mikroenema.

SUMMARY:

In this review, the rectal dosageform, enema, that is both locally and systemically efficient has been identified, characterized and classified. Besides, by mentioning the advantage and disadvantage of these rectal applications, clinical and technological investigations on various enema formulations were summarized.

Key Words : Enema, Rectal Absorption, Microenema

\section{GİRIŞs:}

Günümüzde, hasta uyuncunun en iyi olabileceği, etken maddenin istenen ve hedeflenen bölgede istenen zaman aralığında etki gösterebileceği değişik dozaj şekilleri hazırlanarak, aynı etken maddenin farklı dozaj şekilleriyle değişik etkinliklerinin sağlanmasına çalışılmaktadır.

Rektal olarak uygulanmak üzere sıvı, yarı katı ya da katı dozaj şekilleri hazırlanmaktadır. $\mathrm{Bu}$ amaçla sıvı ve yarı katı grubuna dahil edebileceğimiz enemalar, hidrojeller, köpükler, rektal kapsüller ve supozituvarlar; katı formülasyonlar grubuna dahil edebileceğimiz katı dispersiyonlar, mikrokapsül ve osmotik pompa gibi henüz deneme aşamasında olan bazı dozaj şekilleri bulunmaktadır (1). 
Rektal absorpsiyon daha çok dozaj şeklinin anüse uygulanmasından sonra kalın barsağın distal bölgesine ulaşması, sonra rektal ampula, sigmoid ve inen (descending) kolona ulaşmasıyla gerçekleşmektedir (Şekil 1).Kolonda ince barsaktan daha az bir yüzey alam olduğu için absorpsiyon da azalmaktadır. pH' sı 7-8 olan birkaç mililitrelik rektal sıvının tamponlama kapasitesi de düşüktür. Rektuma kan, inferior rektal arterlerle gelmekte ve superior, medial ve inferior venlerle geri direne edilmektedir. Karaciğer ya da sistemik dolaşıma geçiş için kesin bir anatomik ayrım yapılmamıştır (Şekil 2). Bu sebeple de oral olarak verildiğinde ilk geçiş etkisine uğrayan bir maddenin rektal uygulama sonunda ilk geçiş etkisine uğramayacağı ya da biyoyararlanımının daha iyi olacağı gibi bir genelleme yapilamamaktadır (1).

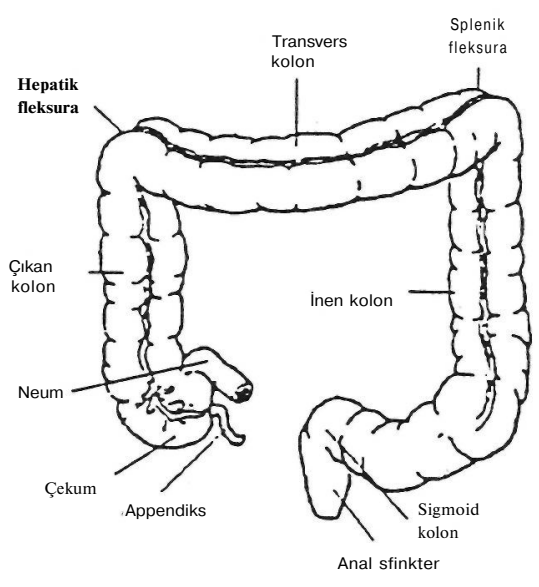

Şekil 1 : Kolon anatomisi (1)

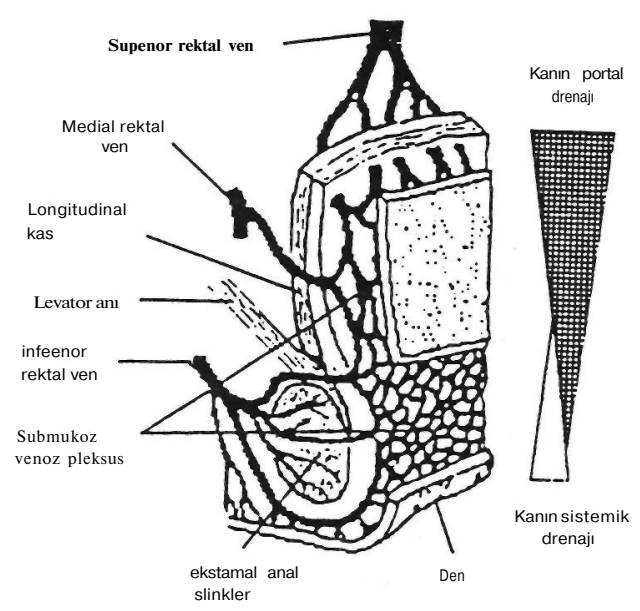

Şekil 2 : Rektumun kan drenaj bölgesi (1)

\section{Rektumdan Absorpsiyon Mekanizması :}

Rektumdan ana absorpsiyon mekanizmasının pasif difüzyon olduğu belirtilmektedir; bu da sulu çözelti ve etken maddenin dağılma katsayısı ile ilgilidir. Çok az alkaliye kayan rektum mukozasından zayıf bazik etken maddeler, yağda çözünür, noniyonize formda olan maddeler kolayca absorbe olurlar. Bununla beraber, uygun şartlarda zayıf asitlerin rektal absorpsiyonunun da tam olduğu tespit edilmiştir $(1,2,3)$. Etken maddenin mukozal sekresyon ile mukoza duvarının lipid membranı arasına dağılması için yağ/su partisyon katsayısının orta bir seviyede olması gerektiği bildirilmiştir (2).

\section{Rektal Uygulamaların Avantajlı ve Dezavantajlı Yönleri:}

Rektal uygulama ile gastrointestinal kanalda (GIK) stabilite problemi olan maddelerin verilmesi sağlanmaktadır. Oral yolla verildiğinde mide bulantısına sebep olan ilaçların rektal verilişi ile bu durumun önüne geçilmeye çalışılmaktadır. Pek çok madde ile yapılan karşışşırmalı çalışmalarda biyoyararlanım açısından rektal uygulamalar intravenöz (IV) verilişten sonra ikinci 
sırada yer almaktadır. Ayrıca lokal tedavi için de bu yolla uygulama yapmak bazı avantajlar sağlamaktadır $(1,2)$. Ancak bu avantajların yanısıra rektal uygulamalarda da bazı dezavantajlarla karşılaşmak mümkündür. Örneğin, GIK' da irritan etki yapan çoğu madde rektumda da irritan etki yapabilmektedir. Aynı etken maddenin oral çözeltilerinin uygulanması ile karşılaştırıldığında rektal olarak uygulama sonucunda elde edilen kan seviyelerinin daha değişken olduğu belirlenmiştir. Ayrıca feçesin olup olmaması da rektal uygulamalardaki absorpsiyonu etkileyebilmektedir. Bunun dışında ilacın uygulanması sırasında vücut konumunun durumu gibi bazı faktörler bile absorpsiyonu etkileyebilmektedir. Rektal uygulamalarda kullanılan dozun genelde oral ve intra venöz uygulamalar için gerekenden daha fazla olması da rektal uygulamalardaki dezavantajlardan biri olarak sayılabilir (1$5)$.

Rektal verilerin gösterdiği kadarıyla supozituvar ile yapılan çalışmalarda uzun süreli supozituvar kullanımıyla irritasyonun arttığı gözlenmiştir. Supozituvar formülasyonunda kullanılan sıvağ, yardımcı maddeler ya da tüm kombinasyonun etkisi ile yanma, ülser, rektal kanalda daralma ve absorpsiyonun düzenlilik göstermemesi gibi nedenlerle, rektal uygulamalarda supozituvar yerine enema, hidrojel, çözelti, süspansiyon ya da emülsiyon gibi sıvı ya da yan katı formülasyonlar denenmiştir. Enemalarla rektumda daha iyi bir yayılmanın sağlanması da bu görüşü desteklemektedir. Enemalarla inen kolon ve transvers kolonda yayılmalar olduğu radyoopak madde verilişi ile tespit edilmiştir; uygulanan formülasyonun çoğunun rektumda kalması söz konusu olsa da kolonun daha üst kısımlarına yayılma enemalarda supozituvardan daha iyi olmaktadır $(1,2)$.

\section{Enemaların Tanımı ve Sınıflaması :}

Enemalar, çeşitli amaçlarla rektum içine enjeksiyonla uygulanan çözelti, emülsiyon ya da süspansiyonlardır (1,4,6-9). Enemaların kullanım amaçlarına göre değişik şekillerde sınıflandırılmaları yapılabilmektedir.

Genel olarak enemalar;

1 ) Barsakları boşaltmak için kullanılan \{Evacuant-Evacuation) enemalar,

2 ) Absorpsiyonla sistemik etki için hazırlanan Retansiyon (Retention) Enemaları,

3 ) Rektal bölgedeki rahatsızlıklarda lokal etki amacıyla hazırlanan enemalar şeklinde sınıflandırılabilirler $(4,9)$.

Farklı sınıflara ayrılan enemalar arasındaki başlıca farklılık uygulama hacimlerinden kaynaklanmaktadır. Barsak boşaltıcı enemalar 2 litreye kadar varan hacimlerde kullanılırken, retansiyon enemalarının hacmi bazı kaynaklara göre yetişkinlerde 100 mL'yi aşmazken (7), bazı kaynaklara göre de yetişkinlerde 150-300 mL'ye kadarki hacimlerde kullanılabilir $(6,9)$.

Hacimlere göre farklı gruplar halinde düşünüldüğünde, son zamanlarda en fazla güncelleşmiş olan mikro ya da mini enemalar da bir başka grup olarak ele alınabilir. Mikro enemalar 2-3 mL gibi 
çok küçük hacimlerde uygulanmakta olup, aslında kullanım amacı açısından retansiyon enemalarıyla aynı grup altında incelenmeleri de mümkündür $(1,4,9)$.

\section{Barsak Boşaltıcı (Evacuant) Enemalar :}

Barsakları boşaltmak için kullanılan enemalarla laksatif ve pürgatif etki gözlenmektedir. Çoğu laksatif ve pürgatif etkili ilaç oral olarak kullanılmaktaysa da bazı ilaçlar da enema ve supozituvar şeklinde kullanılmaktadır. Genelde barsak boşaltıcı enema tarzında verilen ilaçlarla osmotik dengenin dışarıdan verilen iyonlarla bozulmasıyla defekasyonun artırılmasına yönelik uygulama yapılmaktadır

Boşaltım amacıyla kullanılan bu büyük hacimli enemalara en basit ve tipik örnek sabunlu enemalardır.Bunun dışında nişasta müsilajı da barsak boşaltıcı enemaların hazırlanmasında, çözünmeyen katılan süspande etmek amacıyla emoliyan olarak kullanılmaktadır. Sodyum karboksimetil selüloz (Na-CMC) da yine bu amaçla bu tip enemalarda süspande edici madde olarak kullanılmaktadır Nişastalı enemalar tek başına ya da başka enemalara sıvă̆ olacak şekilde kullanılmaktadırlar $(7,10)$. Bunun dışında en çok sodyum klorür, sodyum bikarbonat, sodyum mono hidrojen fosfat barsak boşaltıcı enema olarak kullanılmaktadır. Bu maddeler tek başlarına kullanıldıkları gibi birbirleriyle kombine halde ya da sabun gibi irritan bir madde ile birlikte de kullanılmaktadırlar. İyon kaynağı olan bu enemalarla laksatif ve pürgatif etki sağlanmış olmaktadır. Barsak boşaltıcı enemalar genellikle vücut sıcaklığına getirildikten sonra bir şırınga yardımıyla vücuda verilmektedir $(6,9,11,14)$.

\section{Retansiyon (Retention) Enemalar:}

Absorpsiyonla sistemik etki elde etmek amaciyla hazırlanan enemalardır. Bu tipte hazırlanan enemaların büyük hacimde olanlarının yanısıra daha çok mikroenema tarzında verilmeleri tercih edilmektedir. Ameliyatlardan önce bazal anestezik maddeler rektal injeksiyonla enema tarzında uygulanabilmektedir. Mesela tiyopentan sodyum ile vücut ağırlığının her kilogramı başına 40 mg'lık dozlar halinde maksimum $2 \mathrm{~g}$ olacak şekilde $30 \mathrm{~mL}$ distile suda çözülerek, taze hazırlanıp uygulanan bir retansiyon enema hazırlanmıştır. Paraldehit'in \%0.9' luk sodyum klorür çözeltisi içindeki \%10' luk preperatı da yine retansiyon enema olarak hazırlanan enemalardandır (7). Aminofilin, hidrokortizon ve metil prednizolon asetat gibi resmi olarak kayıtlı olan bazı retention enemaları da bulunmaktadır $(9,12,13)$. Bu tip enemaların $150 \mathrm{~mL}^{\prime}$ nin üstünde kullanılmaması tavsiye edilmektedir. Hatta mikroenema şeklindeki kullanımları tercih edilmektedir. Valpronik asit, indometazin, metronidazol gibi etken maddelerle absorpsiyon amaçlı mikroenemalar hazırlanmıştır (9).

\section{Mikroenemalar:}

Mikroenemalar 3-10 mL'lik süspansiyon ya da su içinde, propilen glikol ya da etanol içindeki çözeltiler şeklinde hazırlanmaktadır $(1,9,15)$. İhtiyaca göre bazı viskozite artırıcı maddeler de formülasyona ilave edilmektedir. $10 \mathrm{~cm}$ kadar uzunluktaki dış tüpü olan bir küçük plastik kapta ambalajlanırlar. Parmak basıncı ve bu tüp aracılığı ile rektuma kolayca uygulanması săglanmaktadır. 
$\mathrm{Bu}$ apereyin ya da tüberkülin şırıngalarının kullanımı normal şırınga kullanımına göre daha uygun bulunmuştur (4).

Sistemik amaçlı enemalarla supozituvardan daha iyi bir absorpsiyon sağlanabilmektedir; çünkü taşıyıcı fazın çok büyük bir kısmı barsakların daha uzunca bir bölgesini kapsayabilmektedir, böylecede en azından rektal mukoza boyunca absorpsiyon sağlanabilmektedir. Ancak genel olarak enemaların vücut dayanıklılığı fazla olmayan zayıf hastalarda uygulanması zararlı olabilmektedir. Gebeliğin son dönemlerinde, akut apandisit rahatsızlıklarında da kullanımları tavsiye edilmemektedir. Uzun süreli kullanımlarında barsak travmalarına da neden olabilmektedir $(1,4)$.

Günümüz teknolojisinde her geçen gün önem kazanan retansiyon enema formülasyonlarına ait çalışmalar son 20 yılda giderek artmıştır. Bunlardan oldukça önemli bir grubu özellikle ülseratif kolit tedavisinde lokal olarak kullanılmakta olan 5-Arninosalisilik asit (5-ASA) enemalarla yapılan çalışmalar oluşturmaktadır (16-31).Ülseratif kolit tedavisinde kortikosteroitlerle uzun süreli tedavi yapıldığında bazı yan etkiler tespit edildiği için aynı amaçla 5-ASA kullanılmış ve daha etkin olduğu tespit edilmiştir $(21,23)$. Oral olarak sülfasalazin preparatları da bu amaçla kullanılmakta, ancak oral kullanımla barsaktaki floradan dolayı metabolize olarak 5-ASA ve sülfapiridin'e dönüşmektedir. Sülfapiridin'in yan etkilerini elimine etmek için rektal olarak 5-ASA'nın enema olarak verilişi denenmiştir. Supozituvara göre kolonda yayılma ve mukoza ile temasın daha iyi sağlandığı belirlenmiştir (24). CAMPIERI ve arkadaşları (16), mesalazine (5-ASA) eneması ile hastalara yaptıkları uygulama sonucuna dayanarak özellikle de yaygın iltihaplanma olan durumlarda enema kullanımının daha uygun olduğunu bildirmişlerdir. Yapılan çalışmalarla hem formülasyona ait hem de hastanın fizyolojik, anatomik koşullarına ait değişikliklere dayanarak incelemeler yapılmıştır. TIEL van BUUL ve arkadaşları (19), yaptıkları çalışmada distal kolondaki yayılmada etkili formülasyon parametrelerinden enema hacminin ve viskozluğun etkin bir faktör olabileceğini belirtmişlerdir. Bu araştırmacılar, büyük hacimdeki ve düşük viskozluktaki 5-ASA enenıasının etkinliğini sintigrafik inceleme yaparak tespit etmişlerdir.

ALMER ve arkadaşları (31) da 5-ASA'nın kitre zamkı ve polivinil pirolidon'un süspande edici madde olarak kullanıldığı, pH'sı 5.2-5.3 olan süspansiyon formülasyonunu hazırlamışlardır. Plazma, idrar ve feçesten yüksek basınçlı sıvı kromatografısi analizi ile 5-ASA'nm emilimini incelemişlerdir. Çalışma sonucunda 4g 5-ASA kullandıkları halde pH 7.4 olan lg 5-ASA eneması ile elde edilen pik plazma seviyesinden daha düşük bir kan plazma seviyesi elde etmişlerdir. Aynı araştırmacılar çalışmalarında pH'sı 5.5-5.8 olan 4g 5-ASA eneması ile de karşılaştırdıklarında, 5-ASA'nm pH 4-7 aralığında çözünürlüğünün düşük olduğu, bu nedenle pH'nın nötre yakın olduğu enema formülasyonu ile daha düşük dozda etken madde içermesine rağmen daha iyi bir absorpsiyon elde edildiğini tespit etmişlerdir. Ayrıca oral verilişe göre de daha iyi bir plazma seviyesi elde edildiğini saptamışlardır. 
Yine 5-ASA'nın incelenmesi için yapılan bir çalışmada VITTI ve arkadaşları (17), hazırladıkları süspansiyon formülasyonunda süspansiyon içeriğinin yayılmayı etkileyeceğini göz önünde bulundurarak, çalışmadaki radyolojik incelemelerde baryum sülfat veya metilselüloz'un inklüzyonlarının yayılmayı etkileyeceği düşüncesiyle sadece ${ }^{99 \mathrm{~m}} \mathrm{Tc}$ ile işaretleme yapmışlardır.Başka bir çalışmada da, baryumun viskoziteyi değiştireceği ve böylece de radyolojik ölçüm yapılırken belki de enemanın gerçek yayılma şeklinin gözönünde bulundurulamayacağı düşüncesiyle sadece ${ }^{99 m} \mathrm{Tc}$ kullanılmıştır.

Formülasyonun etkin olması için yapılan çalışmalarda, 5-ASA'nın sudaki stabilitesinin iyi olmadığı gözlendiği için Xanthan zamkı (Keltrol), ve 5-ASA'dan oluşan bir karışım hazırlanmıştır. Kuru süspansiyon olarak hazırlanan bu karışımın $37^{\circ} \mathrm{C}^{\prime}$ lik suda, kullanmadan hemen önce 3-4 dakika karıştırılması ile 3-6 saat stabil kalabilen enema formülasyonu elde edilmiştir $(22,25,26)$. MONTGOMERY ve arkadaşlarının (24) 5-ASA süspansiyon formülasyonu ile oda ve buzdolabı sıcaklıklarında yaptıkları stabilite çalışmaları 90 gün boyunca etken maddenin \%90'ının muhafaza edilebildiğini göstermiştir.

5-ASA enemalarının sulu çözeltilerindeki stabilite problemlerini düzeltmek üzere ve 5ASA'nın pahalı olması sebebiyle başka alternatifler aranırken 4-ASA sodyum tuzunun da ülseratif kolit'de 5-ASA veya N-asetil 5-ASA ile aynı etkinlikte olduğu bulunmuştur. Sülfazalazin ve onun aktif komponenti 5-ASA'nın etki mekanizması tam olarak bilinmemektedir. Yapılan çalışmalar, ASA'ya bağlanan 4. veya 5. pozisyondaki amino gruplarının etkide değişiklik yapmadığını ortaya çıkarmıştır. 4-ASA daha stabil ve ucuz olduğu için ülseratif kolit'in lokal tedavisinde alternatif olarak kullanılabileceği sonucuna varılmıştır (23).

4-ASA ve 5-ASA enemalarını aynı dozlarda hazırlayan bazı araştırmacılar, iki hafta boyunca bu enemaları çift körle birlikte denemişler, semptomatik, sigmoidoskopik ve de histolojik yararlılıklarının benzer olduğunu bulmuşlardır (25). 4-ASA'nın en önemli üstünlüğü kolay sentezlenmesi, sulu çözeltilerinin stabil olması ve de ucuz olmasıdır. GINSBERG ve arkadaşları (21), 4-ASA'nın retansiyon eneması ile 8 haftalık inceleme yapmış, klinik olarak bir haftada, sigmoidoskopik ve histolojik olarak daha uzun bir zamanda iyileşme olduğunu, ancak 8 hafta sonunda biyopsi sonuçlarına göre enflamasyonun kalmadığını 8 haftada 12 hastadan 10'unun klinik olarak iyileştiğini tespit etmişlerdir.

5-ASA'ya alternatif olarak bizmut sitrat ve polisakkarit kompleksi içeren enemalar denenmiştir. 65 hasta üzerinde 4 haftalık bir tedavi süreci geçirilmiştir.Hastalar klinik ve sigmoidoskopik olarak ve rektal biyopsi incelemelerine göre bizmut sitratlı enema ile de 5-ASA enemalarındaki kadar iyileşme göstermiştir. Bizmut enemasının formülasyonunda kullanılan carbopol 934P (poliakrilik asit), enemaya jel formunu vermektedir. Mukusa benzer bir yapı oluşması, bu 
enemanın daha iyi adhere olmasını sağlamıştır; böylece de 5-ASA kadar etkin olmuştur (Bizmut sitrat peptik ülserde helicobacter pylari'nin yok edilmesi için kullanılmaktadır) (29).

5-ASA enemalarından daha iyi sonuç alabilmek için köpük formu hazırlanmış, bu şekilde yayılmanın daha iyi olabileceği düşünülmüsstür $(1,28)$. Şekil 3'de de görüleceği gibi, istatistiksel olarak enema ile köpük arasında tedavi açısından anlamlı bir farklılık gözlenememiştir (30).

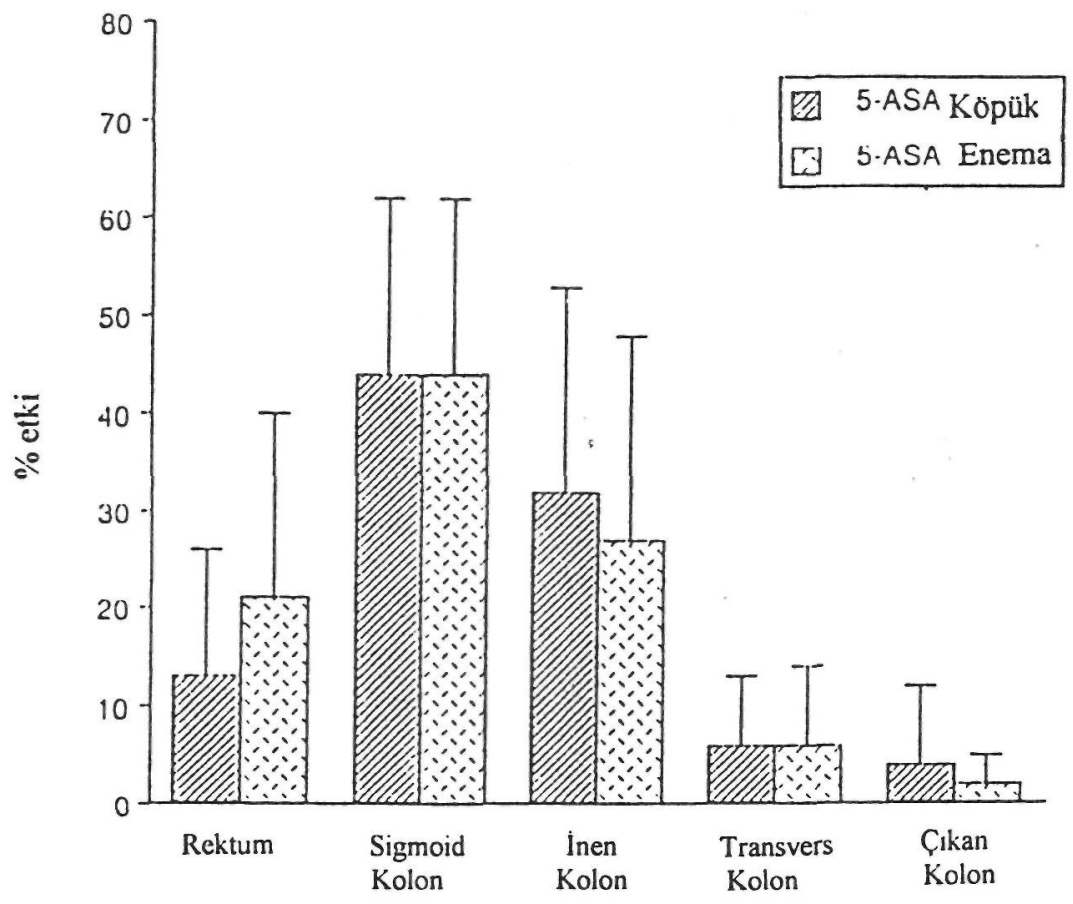

Şekil 3: Radyolojik olarak işaretlenmiş olan 5 ASA köpük ve 5 ASA enemanın uygulamadan sonraki 2. saatte barsaktaki bölgesel dağılımı (30).

Oral kullanımında nefrotoksik etkisi gözlenen siklosporin'in de topik kullanım ile barsak iltihabının tedavi edilmesinde enema formülasyonu denenmiştir. Yapılan bir çalışmada, siklosporin'in parenteral preparatına sorbitol ve Na-CMC ilavesi ile hazırlanan retansiyon enemasının uygulanmasından sonra sigmoidoskopik inceleme ve rektal biyopsi sonuçlarına göre iyileşme tespit edilmiştir (32). Daha sonraki yıllarda bu çalışmalara dayanarak denemeler devam etmiş ve IV, oral ve enema uygulamaları karşılaştırmalı olarak çalışılmıştır. İki farklı enema formülasyonu hazırlanan siklosporin'in, oral çözeltisinin $60 \mathrm{~mL}$ zeytinyağında hazırlanmış olan eneması ile oral çözeltinin 5g sorbitol, 500mg karboksimetil selüloz (CMC) ilavesinden sonra $60 \mathrm{~mL}$ ' ye su ile tamamlanması ile hazırlanan eneması, IV ve oral çözeltilerle karşılaştırılmış, kandaki siklosporin miktarı ve sigmoidoskopik doku tayini ile elde edilen sonuçlar, siklosporin'in yağlı ve sulu enemalarından sistemik absorpsiyonunun dikkate alınamayacak kadar az olduğu halde, kolonik doku 
konsantrasyonlarının oral ve IV uygulamaya göre 10 kat daha fazla olduğunu göstermiştir Bu sonuç siklosporin enema formülasyonunun kolit tedavisinde uygulanabileceğini göstermektedir. (33). Benzer sonuçlar WINTER ve arkadaşları (34) tarafından yapılan çalışmalarda da elde edilmiştir .

Son yıllarda üzerinde çokça çalışma yapılan polipeptit ilaçların pekçoğu parenteral injeksiyonla uygulanmaktadır. Oral verilişleri oldukça problemli olan bu ilaçların parenteral verilişine bir alternatif olarak da rektal enemalar denenmiştir. YOSHIOKA ve arkadaşları (35), gastrin ve pentagastrin'in mikroenemalarını hazırlamışlar ve 5-metoksi salisilat içeren ve içermeyen enemaları 5-metoksi salisilat içermeyen IV çözeltilerin uygulanması ile karşılaştırılarak 5-metoksi salisilatlı enemalarla emilimin bariz şekilde arttığım tespit etmişlerdir (Şekil 4).

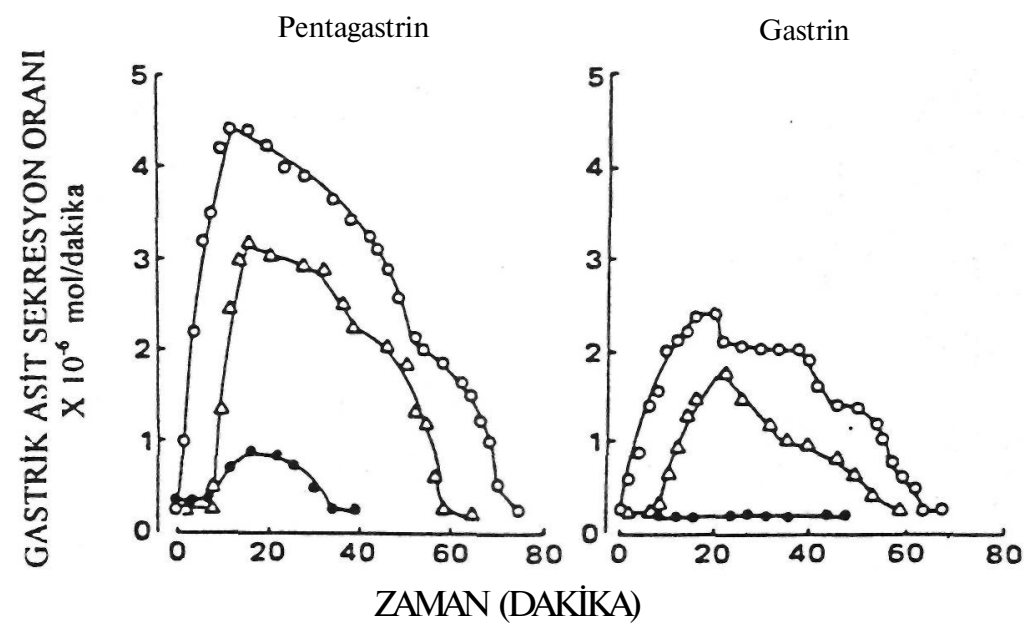

Şekil 4: Anestezi altında bulunan ratlarda gastrin ve pentagastrin uygulamasını takiben gözlenen gastrik asit sekresyon profili. Ratlara uygulanan çözeltiler; Intravenöz olarak izotonik $\mathrm{NaCI}$ çözeltisindel $25 \mu \mathrm{g}$ polipeptid/ $\mathrm{kg}$ (o); rektal olarak izotonik $\mathrm{NaCl}$ çözeltisinde 12.j. polipeptid/kg pH 8.0 (o) ve rektal olarak izotonik $\mathrm{NaCl}$ çözeltisindeki $125 \mu \mathrm{g}$ polipeptid/ $\mathrm{kg}$ rat ve $25 \mathrm{mg}$ 5-metoksisalisilat $\mathrm{pH} 8.0$ ( ) (35).

Oral absorpsiyonu sorunlu olan insülinle de çalışılmış ve hazırlanan enemalardan insülin absorpsiyonunu artırmak için yüzey aktif maddelerin (YAM) kullanımı denenmiştir; ancak YAM kullanımı da bazen rektal kanamalara neden olmaktadır. Fenilalanin'in derivesi olan enamin'in kullanımı ile mikroenema ve supozituvar uygulaması denenmiş ve karşılaştınlmıştır. \%4 Jelatin çözeltisinde hazırlanmış olan enemalara sodyum fenilalanin'den elde edilen etilasetoasetat enamin ilavesi ile oldukça uzun süre ve yüksek seviyede serum insülin seviyesi tespit edilmiştir (Şekil 5 ).SUMI KIM ve arkadaşları (36) rektal supozituvarlardan insülin çıkışının enemadan çıkıştan daha az olduğunu ileri sürmüşlerdir. Yine aynı araştırmacılar, farklı enema ve supozituvarlarda insülin'in rektal absorpsiyonunu incelemek üzere yaptıkları bir çalışmada \%4 jelatin içeren ve içermeyen enemalarla Witepsol H15 ile hazırlanan supozituvarlardan en yüksek biyoyararlanımın \%4 jelatin içeren enema formülasyonunda olduğunu tespit etmişlerdir. Jelatinli enema formülasyonunda, yine aynı araştırmacıların daha önce gastrin ve pentagastrin ile yaptıkları çalışmada da olduğu gibi sodyum 
5-metoksisalisilat'ın 300mg sodyum salisilat'tan daha fazla etkili olduğu gözlenmiştir.\%4 Jelatinli formülasyonla insülin'in daha az dozu ile etki sağlanabilmiştir. Öte yandan supozituvarlarda 5-metoksi salisilatlı formüllerde de insülin'in düşük absorpsiyon göstermesini kristal haldeki insülin'in supozituvar sıvağındaki çözünürlüğünün az oluşu ile izah etmişlerdir. Supozituvar formülünde yer alan 5-metoksi salisilat, insülin çıkışı olana kadar çoktan salınıp absorblanmış olduğu için kullanılan bu absorpsiyon artırıcı maddenin herhangi bir etkisi gözlenememiştir. Araştırmacılar, absorpsiyon artırıcı madde ve etken maddenin aynı anda çıkışı olmalı sonucuna varmışlardır (37).
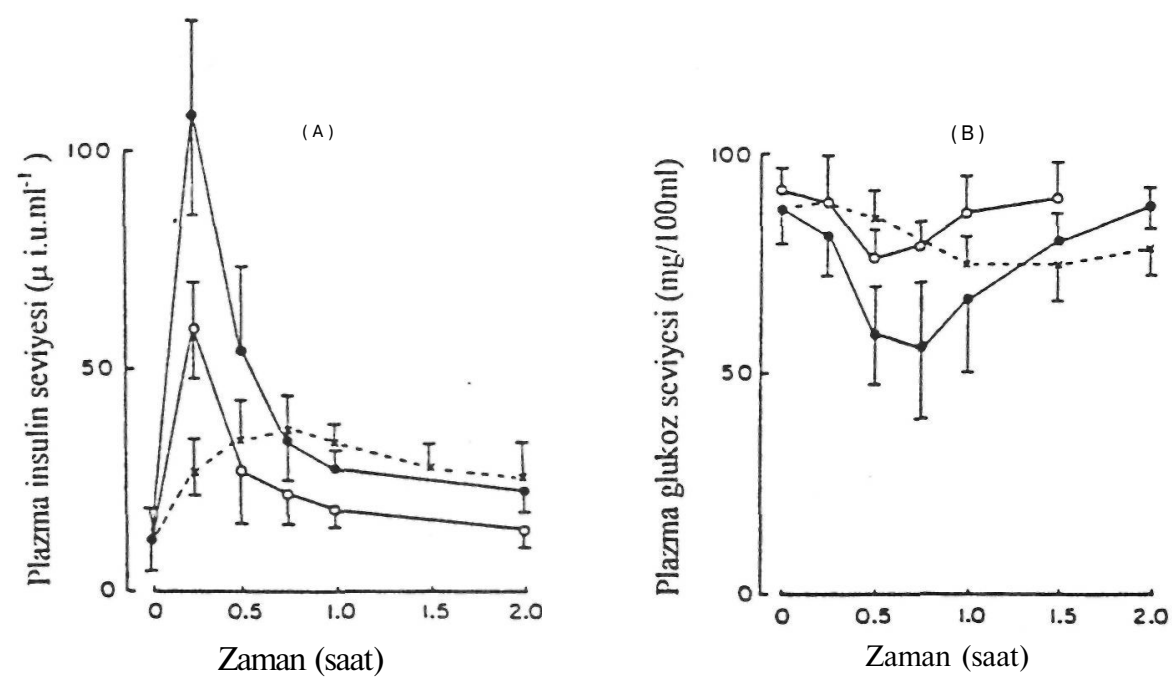

Şekil 5:Köpeklerde; 2 i.u.insulinin intramuskuler injeksiyonunu (x),Witepsol H15 ile hazırlanmış 12 i.u. insulin ve $150 \mathrm{mg}$ etilasetoasetat enamin Na içeren $1 \mathrm{~g}$ supozituvarın rektal uygulamasını (o), \% 4 jelatinle hazırlanmış, 12 i.u. insulin ve 150mg etilasetoasetat enamin $\mathrm{Na}$ içeren lg enema uygulamasını (o) takiben tespit edilen plazma insulin (A) ve glukoz (B) seviyeleri (36).

5 Florourasil de rektal olarak absorblanamadığı için 3-açil,lalkoksikarbonil ve 3-açiloksi metil prodrugları rektal ve oral olarak hazırlanmış ve denemelerde bileşiklerin metil selüloz içeren $\mathrm{pH} 7.4$ fosfat tampon içindeki sulu çözeltileri hazırlanmıştır. Bazı bileşiklerin çözünürlükleri az olduğu için süspande şekilde kalmışlardır. Bu çalışmada hazırlanan formülasyonlarla \%90'dan daha fazla rektal biyoyararlanım gösteren bileşikler olduğu saptanmıştır. Bu araştırmada aynı zamanda partisyon özellikleri de incelenmiştir; çünkü, çok az olan rektal sıvıdaki çözünürlük ne kadar artarsa o kadar iyi absorpsiyon olacaktır. Oktanol-sulu tampon (pH7.4) arasındaki partisyon katsayısının 0.5'den büyük olması halinde sudaki çözünürlüğün artacağı tespit edilmiştir. Partisyon katsayısının ayarlanması ile absorpsiyonun artırılabileceği tespit edilmiştir (38).

Oral biyoyararlanımı rektal ile karşılaştırılan bir başka madde de ampisilin'in prodrug'1 olan bakampisilin HCl'dir. Bakampisilin \%0.5' lik metilselüloz çözeltisi içerisinde pH'sı 3.3 olan 
mikroenema formülasyonu hazırlanmıştır. Ancak oral uygulama ile kıyaslandığında düşük biyoyararlanım elde edilmesi, küçük absorpsiyon yüzeyinden, $\mathrm{pH}$ 7-8 civarındaki rektal pH'da etken maddenin çözünürlüğünün az oluşundan ve rektum tamponlama kapasitesinin çok az olmasından kaynaklandığı kanısına varılmışır. Ayrıca viskozite artırarak rektal mukoza ile temasın artırılmasına çalışılırken bakampisilin'in metil selüloza bağlanmış olması ihtimali de ileri sürülmüş, hatta bu bağlanmanın azalabilmesi için ultrafiltrasyon yapılmıştır (39).

Akut astım vakalarında $\beta_{2}$ sempatomimetik ilaçlara ilaveten teofilin'in IV uygulamaları da yapılmaktadır. Teofilin, diprofilin, proksifilin kombinasyonu ile hazırlanan retansiyon enemasının teofilin-etilendiamin IV formülasyonu ile karşılaştırmasının yapıldığı bir çalışmada enema ile IV uygulamaya göre daha uzun bir sürede maksimum seviyeye ulaşmasına rağmen, yüksek serum teofilin seviyesi sağlayabildiği ve daha uzun süreli olarak etkin konsantrasyonda kalabildiği tespit edilmiştir (40). Teofilinle yapılan rektal çalışmalardan henüz net bir sonuç alınamamasına rağmen bir başka çalışmada da oral teofilin eliksiri ve enema formülasyonları karşılaştırılmış ve biyoyararlanımlarının yakın olduğu belirlenmiştir (41).

Mikroeneması hazırlanarak parenteral verilişe bir alternatif olarak çalışılan etken maddelerden biri de diazepam'dır. Dental cerrahide ve özellikle çocuklardaki epilepsi tedavisinde oral ya da parenteral olarak kullanılabilen bu etken maddenin sudaki çözünürlüğünün az oluşu preparat hazırlanışında bazı problemler çıkarmaktadır. Organik çözücülerden dolayı, enjeksiyon bölgesinde ağrı ve yanma olması, diğer IV infüzyon çözeltileri ile birlikte verildiğinde çökmesi ve de plastik materyallerle sürekli infüzyon sırasında absorbe olması gibi sorunlar, bu maddenin bir de rektal verilişinin denenmesine sebep olmuştur (42-47).

ROELOFSE ve arkadaşları (43), dental cerrahide özellikle çocuklarda anestezi uygulamadan 30 dakika önce uyguladıkları $0.70 \mathrm{mg} / \mathrm{kg}$ diazepam ve $0.35 \mathrm{mg} / \mathrm{kg}$ midazolam'ın rektal uygulamalarını yaparak karşılaştırmışlar ve pediatrik anestezide ağrısız olması nedeniyle bu uygulamayı tercih etmişlerdir. Her iki madde ile de başarılı sonuçlar elde edilmiştir. Epilepsili çocuklarda yapılan bir çalışmada da IV uygulama kadar etkin olduğu ispatlanan rektal diazepam'ın denemeleri yapılmıştır (Rektal doz : 0.2-0.5 mg/kg, IV doz: 0.1-0.3 mg/kg). Daha kolay uygulama olması ve eşit etkinlik IV yerine rektal diazepam'ın da özellikle bebeklerde tercih edilebileceğini göstermiştir. Rektal uygulama ile solunumla ilgili problemler de azalmıştır (44).

20 çocuk ile yapılan bir başka çalışmada da rektal diazepam uygulamasından 3-5 dakika sonra antikonvülzan konsantrasyonu, 4-6 dakika sonra da sedasyon ve relaksasyon sağlanmıştır.Aynı zamanda rektal verilişte mikroenemaların IV formülasyonu gibi irritan etki yapıp yapmadı̆̆ test edilmiştir. Stesolid ${ }^{\mathrm{R}}$ (Rektal tüp içinde $10 \mathrm{~mL}$ 'lik çözelti) uygulaması yapılmış, uygulanan enema formülü; propilen glikol- alkol- su karışımından oluşan ve diazepam içeren preparattır. Farklı hacimlerde uygulanan enema ile 144 uygulamadan 3'ünde endoskopik olarak irritasyon gözlenmiştir. 
Ancak oluşan \%2'lik irritasyonun sadece etken maddeden mi yoksa etken madde ile çözelti kompleksinden mi ileri geldiği tam olarak tespit edilememiştir. Ancak, 0.5mg/kg'lık dozdaki rektal çözeltilerin yetişkinlerde hafif yanmalara rağmen kullanılabileceği sonucuna varılmıştır (45). MOOLENAAR ve arkadaşları (46), ise irritasyon olayını daha detaylı olarak ele alıp, farklı çözücülerle hazırlanan enemalarla karşılaştırma yapmışlardır. pH'sı 5.2 olan su ile hazırladıkları enema ile, pH's1 4.8 olan propilen glikol-alkol-su $(4+1+5)$ formülü ve pH's1 3.6 olan glukofurol-alkolsu $(5+1+4)$ formülü ile diazepam uygulaması yapılmıştır. 10 sağlıklı denekte yapılan çalışma sonunda bu içeriklerin birbirlerine göre irritasyon açısından anlamlı bir farklılık göstermediğine karar verilmiştir.Ancak, küçük hacimde kullanılmasının tercih edilmesi gerektiğine karar vermişlerdir .

Araştırmacılar, bazı etken maddelerin çözünürlük özelliklerinden dolayı, mikroenema uygulamaları sırasında karşılaşılabilecek irritasyon sorununun önüne geçmek için çözünürlük artırılması çalışmalarına yönelmişlerdir.Siklodekstrinlerle etken maddenin enemadaki çözünürlüğü artırılarak absorpsiyonunun artırılmasına çalışılmıştır $(47,48)$. Diazepam ile $\beta$ siklodekstrinlerin oluşturduğu komplekslerle sudaki çözünürlüğün ve absorpsiyonun arttığı belirlenmiştir, $\beta$ siklodekstrinlerin tercih nedenlerinden biri de rektal irritasyonunun olmamasıdır. Siklodekstrinler ve etken madde- siklodekstrin kompleksi rektumdan absorblanamazlar; ancak kompleksasyon absorpsiyon hızını da anlamlı derecede azaltmamaktadır; çünkü kompleksleşmiş etken maddenin mukustaki lipidlerle yer değiştirdiği düşünülmektedir. Bu etki, mukus ve safra tuzları ile fenolftaleinle yapılan in-vitro yer değiştirme çalışmaları ile de ispatlanmıştır. Araştırmacılar, bu olayı, kompleksten absorbe olan serbest etken maddenin yerine yeniden hızlıca doluşu ve rektal sıvının az oluşu nedeniyle açı̆̆a çıkan etken maddenin dilüe olmadan absorpsiyonunun hemen sağlanabilmesine bağlamışlardır. Böylece süspansiyon tarzında hazırlamak yerine $\beta$ siklodekstrinlerle daha iyi formülasyonlar hazırlanabileceği düşünülmektedir (47).

MORIMOTO ve arkadaşları (49), hipokalsemik bir peptit hormon olan kalsitonin'in osteoporozda kullanımı için rektal jel hazırlamanın etkin bir alternatif olduğunu göstermişlerdir. Peptitler oral olarak verildiklerinde GIK'da proteolitik enzimler tarafından parçalanırlar, bu da uzun süreli enjeksiyonla tedavi yapılmasını gerektirir ki hastaların bunu kabullenmesi oldukça zor olmaktadır. Bu sorunun ortadan kalkması ve karaciğerden ilk geçiş etkisini elimine etmek için de rektal uygulamalar uygun bulunmuştur. Ancak, büyük molekül ağırlıklı maddelerin rektal absorpsiyonunun sağlanabilmesi için de bazı yardımcı maddelere ihtiyaç duyulmuştur. Bu nedenle araştırmacılar, çalışmalarında carbopol kullanmışlar, $\mathrm{pH}$ ve konsantrasyon değişikliklerinin de rektal absorpsiyonu etkilediğini tespit etmişlerdir. Daha sonraki yıllarda MORIMOTO ve arkadaşları (50), hipertansiyonda kullanılan ve karaciğerden ilk geçiş etkisi söz konusu olan dl-propanol HC1 ve Atenolol'un polivinil alkol hidrojelleri ile hazırladıkları enemalarla yaptıkları çalışmada, kontrollü bir 
salım sağlanabileceğini de göstermiştir. Bu çalışmada pH'dan bağımsız, fakat konsantrasyona bağlı bir salım olduğu tespit edilmiştir.

Oral verildiğinde gastrointestinal yan etkisi olduğu tespit edilen nonsteroidal antienflamatuar bir madde olan indometazin'in de suppozituvar, rektal jel şeklindeki enema, rektal jelatin kapsül formülasyonları ile yapılan çalışmada da pluronik F127 ile sürekli etki sağlanmıştır. Özellikle pluronik F127' nin suda çözünür olması ve zaten yapısında bulunan miseller yapılardan dolayı suda çözünmeyen maddeleri de yapısında taşıyabilmesi bu maddenin avantajlı olmasını sağlamaktadır. Jelin oda sıcaklığında katı halde kalıyor olması da uygulama kolaylıkları sağlamaktadır; ancak az da olsa mukozal irritasyona rastlanmıştır (51).

Metakrilik asit ve metil metakrilat kopolimeri (Eudragit) kullanarak yapılan bir çalışmada araştırmacılar, pentoksifilin'in sürekli etkili formülasyonu için rektal jel formüle etmişlerdir. Çalışmalarında Eudragit L,Eudragit S ve yüksek viskoziteli Eudispert hidrojellerin 3 saat sonunda bile rektumun alt bölümlerinde kalıyor olmasını biyoadhezifliğin iyi olmasına bağlamış ve bu uzun süre kalışın çok az olan rektum sıvısından dolaşıma geçişi kolaylaştırdığı ve barsağın alt ve orta rektal venine geçerek interior vena cava' dan geçişi , portal sistem ve karaciğeri bertaraf ederek sistemik dolaşıma geçişinin sağlandığı ve IV'e yakın biyoyararlanım sağlanabileceğini göstermişlerdir. Ayrıca bu jellerin hazırlanmasında kullanılan sodyum hidroksitin biyogeçimli olduğu için tercih edildiği de bildirilmiştir. Kullanılan sodyum hidroksitin miktarına göre de oluşan jellerin parçalanma süresinin değişeceğine de dikkat çekilmiştir (52).

\section{SONUÇ:}

Yapılan tüm bu çalışmalar, son yıllarda rektal uygulamalardaki artışı net bir şekilde göstermektedir. Özellikle diğer uygulama yollarında sorunları olan maddeler için iyi bir alternatif olduğu da yapılan bu çalışmalarla gösterilmiştir. Özellikle de enemaların teknolojik olarak hazırlama kolaylıklarının oluşu, uygulama ve absorpsiyon etkinliğinin oldukça iyi olması, oral olarak uygulanması oldukça sorunlu olan biyoteknolojik ürünlerin vücuda verilişi için iyi bir alternatif olması, bu dozaj formunun yeniden güncellik kazanmasını sağlamıştır. Ancak bu dozaj formlarının da hazırlanmasında ve uygulanmasında bazı sorunlar söz konusu olabilmektedir Önümüzdeki yıllarda bu teknolojik problemlerin yapılacak araştırmalarla düzeltilerek daha stabil ve homojen preparatların hazırlanabileceği kanısındayız. 


\section{KAYNAKLAR:}

1. Gjellan,K.,Graffner,C., "Rectal Drug Administration" Sandell,E,(Ed.) Industrial Aspects of Pharmaceutics Swedish Pharmaceutical Press, Stockholm,264-273 (1993).

2. Wade,A., Pharmaceutical Handbook ,The Pharmaceutical Press,London,p. 308-309(1980).

3. Wagner,J.G., Biopharmaceutics and Relevant Pharmacokinetics ,The Hamilton Press , Illinois, p.214-221(1971).

4. Senior,N., "Rectal Administration of Drugs" Bean,H.S.,Beckett,A.H, Carless,J.E.,(Eds.) Advances in Pharmaceutical Sciences , 4, Academic Press Inc. Ltd, London, 363-435 (1974).

5. Lundgren,S.,Oberg,S., "The Actual Dose Delivery from a Diazepam Enema Differs Depending on the Patients Position During Administration",Swed.Dent. J., 14, 233-239 (1990).

6. Shotton,E.,Ridgway,K, Physical Pharmaceutics,Clarendon Press, Oxford, p.298-299 (1974).

7. Rawlins,E.A., Bentley's Textbook of Pharmaceutics, Cassel\&Collier Macmillan Publishers Ltd., London, p. 350 (1977).

8. Sandell,E., Pharmaceutics, Eric Sandell and Swedish Pharmaceutical Press, Stockholm, p.55 (1982).

9. Remington's Pharmaceutical Sciences 18th. ed. Mack Publishing Co., Easton Pennsylvania, p. 1525 (1990).

10. Kayaalp,0., Rasyonel Tedavi Yönünden Tıbbi Farmakoloji, 3, Ulucan Matbaası, Ankara, p.2736-2750 (1986).

11. British Pharmacopoeia, 2 , HMSO,Crown Copyright, London, (1993).

12. Martindale The Extra Pharmacopoeia, The Pharmaceutical Press, London, 27th. ed.(1977)

13. The United States Pharmacopoeia, The National Formulary, (USP XXII,NF XVII) The United States Pharmacopeial Convention,Inc, Rockville. (1990)

14. Sifton D.W. ed. Physicians' Desk Reference, (PDR, 48th.ed.),p. 945-947 (1994).

15. Rote List, Editio Cantor Verlag fur Medizin,70,179 ( 1991).

16. Campieri,M.,Gionchetti,P.,Belluzzi,A.,Brignola,C.,Tampieri,M.,Iannone,P.,Petronelli,A., Miglioli,M.,Barbara,L., "Role of Rectal Formulations:Enemas", Scand.J. Gastroenterol 22 (suppl 172) 63-65 (1990).

17. Vitti,R.A.,Meyers,F.,Knight,L.C.,Siegel,J.A.,Malmud,L.S.,Fisher,R.S., " Quantitative Distrubition of Radiolabeled 5-Aminosalicylic Acid Enemas in Patients with Left- Sided Ulcerative Colitis", Digestive Diseases and Sciences, 34(11),1792-1797 (1989)

18. D'Albasio,G.,Trallori,G.,Ghetti,A.,Milla,M.,Nucci,A.,Pacini,F.,Morettini,A., "Intermittent Therapy with High-Dose 5-Aminosalicylic Acid Enemas for Maintaining Remission in Ulcerative Proctosigmoiditis", Dis. Colon Rectum, 33, 394-397 (1990). 
19 Tiel van Buul,M.M.C.,Mulder,C.J.J.,Royen,E.A.,Wiltink,H.H.,Tytgat,N.J., " Retrograde Spread of Mesalazine (5-Aminosalicylic Acid) Containing Enema in Patients with Ulcerative Colitis",Clin.Pharmacokinet,20(3),247-251 (1991).

20. Almer,S.,Ekberg,S.,Ström M., "Retrograde Distribution of a New 5-Aminosalicylic Acid Enema in Patients with Ulcerative Colitis", Gastroenterol. Clin.Biol.,16,564-568 (1992).

21. Ginsberg,AX.,Beck,L.S.,McIntosh,T.M.,Nochomovitz,L.E., "Treatment of Left- Sided Ulcerative Colites with 4-Aminosalicylic Acid Enemas", Annals of Internal Medicine, 108, 195-199(1988).

22. Dew,M.J., CardwelI,M., Kidwaı,N.S.,Evans,B.K, Rhodes,J.," 5-Aminosaicylic Acid in Serum and Urine Administration by Enema to Patients with Colitis", J.Pharm Pharmacol 35,323-324 (1983).

23. SeIby,W.S.,Bennett,M.K.,Jewell,D.P., "Topical Treatment of Distal Ulcerative Colitis with 4-Aminosalicylic Acid Enemas", Digestion.,29,231-234 (1984).

24. Montgomery, H.A.,Smith,F.M.,Scott,B.E.,White,S.J.,Gerald,K.B., "Stability of 5-Aminosalicylic Acid Suspension", Am.J.Hosp.Pharm.,43,118-120 (1986).

25. Gandolfo,J., Farthing,M.,Powers,G.,Eagen K.,GoIdberg,M., Berman,P.,Kaplan,M., " 4-Aminosalicylic Acid Retention Enemas in Treatment of Distal Colitis", Digestive Diseases and Sciences, 32(7), 700-704 (1987).

26. Evans B.K., "5-Aminosalicylic Acid", The Pharmaceutical Journal, 19,600 (1983).

27. Baum,C.A.,Biddle,W.L.,Miner,P.B., " Failure of 5-Aminosalicylic Acid Enemas to Improve Chronic Radiation Proctitis", Digestive Diseases and Sciences, 34(5), 758-760 (1989).

28. Campieri, M.,Paoluzi,P.,D'Albasio,G.,Brunetti,G.,Pera,A.,Barbara,L., " Better Quality of Therapy with 5-ASA Colonic Foam in Active Ulcerative Colitis", Digestive Diseases and Sciences,38(10), 1843-1850 (1993).

29. Pullan,R.D.,Ganesh,S.,Mani,V.,Morris,J.,Evans,B.K.,Williams,J.R., " Comparison of Bismuth Citrate and 5-Aminosalicylic Acid Enemas in Ulcerative Colitis: A Controlled Trial" Gut,34,676-679 (1993).

30. Campieri,M.,Corbelli,C.,Gionchetti,P.,Brignola,C.,BeIluzzi,A.,Febo,G.,Zagni,P., Brunetti,G.,Miglioli,M.,Barbara,L., "Spread and Distribution of 5-ASA Colonic Foam and 5-ASA Enema in Patients with Ulcerative Colitis "Digestive Diseasas and Sciences 37(12), 1890-1897(1992).

31. Almer,S.,NorIander,B.,Ström,M.,Osterwald,H., "Steady-State Pharmacokinetics of a New 4-Gram 5-Aminosalicylic Acid Retention Enema in Patients with Ulcerative Colitis in Remission", Scand.J.Gastroenterol,26,327-335 (1991). 
32. Brynskov,J.,Freund,L.,Thomsen,0.,Andersan,C.B.,Rasmussen,S.N.,Binder,V., "Treatment of Refractory Ulcerative Colitis with Cyclosporin Enemas", The Lancet, 1, 721-722 (1989).

33. Sandborn,W.J.,Strong,M.R.,Forland,S.C.,Chase,R.E.,Cutler,R.E., "The Pharmacokinetics and Colonic Tissue Concentration of Cyclosporine After IV, Oral, and Enema Administration", J. Clin.Pharmacol.,31,76-80 (1991).

34. Winter,T.A.,Dalton,H.R.,Merrett,M.N.,Campbell,A.,Jewell,D.P., "Cyclosporin A Retention Enemas in Refractory Distal Ulcerative Colitis and 'Pouchitis", Scand.J.Gastroenterol, 28,701-704 (1993).

35. Yoshioka,S.,Caldwell,L.,Higuchi,T., "Enhanced Rectal Bioavailability of Polypeptides Using Sodium 5-Metoxysalicylate as an Absorption Promoter", Journal of Pharmaceutical Sciences, 71(5),593-594 (1982).

36. Kim,S.,Kamada,A.,Higuchi,T.,Nishihata,T., "Effect of Enamine Derivatives on the Rectal Absorption of Insulin in Dogs and Rabbits", J.Pharm.Pharmacol.,35, 100-103 (1983).

37. Nishihata,T.,RyttingJ.H.,Kamada,A.,Higuchi,T.,Routh,M.,Caldwell,L., "Enhancement of Rectal Absorption of Insulin Using Salisylates in Dogs", J.Pharm Pharmacol, 35, 148-151(1983).

38. Buur,A.,Bundgaard,H., " Prodrugs of 5-Fluorouracil. VIII.Improved Rectal and Oral Delivery of 5-Fluorouracil Via Various Prodrugs. Structure-Rectal Absorption Relationships" Int.J.Pharm.,36,41-49 (1987).

39. Sjövall,J.,Westerlund,D.,Alvan,G.,Magni,L.,Nord,C.E.,Sörstad,J., "Rectal Bioavailability of Bacampicillin Hydrochloride in Man as Determined by Reversed- Phase Liquid Chromatography", Chemotherapy,30,137-147 (1984).

40. Dorow,P.,Schenk,H.,Dougherty,C, " Effect of a Methylxanthine Preparation in the Form of a Retention Enema on Pulmonary Function and Theophylline Levels in Patients with Acute Bronchospasm", Arzneim.Forsch/Drug Res.,36(1),974-976 (1986).

41. Cole,M.L.,Kunka,R.L., "Pharmacokinetics and Bioavailability of Theophylline Following Enema and Suppository Administration in Man", Biopharmaceutics and Drug Disposition 5,229-240 (1984).

42. Pavanetto,F.,Conti,B.,Giunchedi,P.,Genta,I.,Conte,U., "Polylactide Microspheres for the Controlled Release of Diazepam", Eur. J.Pharm.Biopharm.,40(1),27-31 (1994).

43. Roelofse,J.A.,Bijl,V.D., "Comparison of Rectal Midazolam and Diazepam for Premedication in Pediatric Dental Patients", J.Oral. Maxillofac.Surg.,51,525-529 (1993). 
44. Dieckmann,R.A., "Rectal Diazepam for Prehospital Pediatric Status Epilepticus", Annals of Emergency Medicine, 23(2), 216-224 (1994).

45. Hansen,H.C.,Harboe,H.,Drenck,N.E., "Local Irritation After Administration of Diazepam in a Rectal Solution", Br. J.Anaesth,63,287-289 (1989).

46. Moolenaar,F.,Huizinga,T., "Rectale Irritatie van Vehiculae Geschikt Voor Diazepam Micro-klyma"'s", Pharmaceutisch Weekblad,ll6,33-34 (1981).

47. Frijlink,H.W.,Eissens,AC.,Schoonen,A.J.M.,Lerk,C.F., "The Effect of Cyclodextrins on Drug Absorption. II. In vivo Observations", Int.J.Pharm.,64,195-205 (1990).

48. Regdon,G.,Bacskay,L,Kata,M.,Selmeczi,B.,Szikszay,M.,Santa,A.,Balint,G.S., "Formulation of Diazepam Containing Rectal Suppositories and Experiences of Their Biopharmaceutical Study", Pharmazie,49,346-349 (1994).

49. Morimoto,K.,Akatsuchi,H.,Aikawa,R,Morishita,M.,Morisaka,K., "Enhanced Rectal Absorption of $\left(\mathrm{ASU}^{17}\right)$-eel Calcitonin in Rats Using Polyacrylic Acid Aqueous Gel Base", J.Pharm.Sci,73(10),1396-1397 (1984).

50. Morimoto,K.,Fukanoki,S.,Morisaka,K.,Hyon,S.H.,Ikada,Y., " Design of Polyvinyl Alcohol Hydrogel as a Controlled-Release Vehicle for Rectal Administration of dl-Propanolol-HCl and Atenolol", Chem.Pharm.Bull,37 (9),2491-2495 (1989).

51. Miyazaki,S.,Nakamura,T.,Yokouchi,C.,Takada,M., "Effect of Pluronic Gels on the Rectal Absorption of Indomethacin in Rabbits", Chem.Pharm.Bull.,35(3), 1243-1248 (1987).

52. Kim,N.S.,Kawata,M.,Uchida,T.,Goto,S., "Preparation and Evaluation of Eudragit Gels.III: Rectal Gel Preparation for Sustained Release of Pentoxifylline", J.Pharm.Sci, 81(6), 537-540 (1992)

Başvuru tarihi: 05.12.1996

Kabul tarihi : 11.04 .1997 